\title{
Triterpenoid Saponins from Stem Bark of Pentaclethra macroloba
}

\author{
Francisco Arnaldo Viana, ${ }^{a}$ Raimundo Braz-Filho, ${ }^{*, b}$ Yvone B. M. Pouliquen, ${ }^{c}$ Manoel Andrade Neto, ${ }^{c}$ \\ Gilvandete M. P. Santiago ${ }^{c}$ and Edson Rodrigues-Filho ${ }^{d}$ \\ ${ }^{a}$ Departamento de Química, Universidade do Estado do Rio Grande do Norte, 59610-210 Mossoró - RN, Brazil \\ ${ }^{b}$ Setor de Química de Produtos Naturais - LCQUI - CCT, Universidade Estadual do Norte Fluminense, 28013-600 \\ Campos dos Goytacazes - RJ, Brazil \\ ${ }^{c}$ Departamento de Química Orgânica e Inorgânica, Universidade Federal do Ceará, 60021-970 Fortaleza - CE, Brazil \\ ${ }^{d}$ Departamento de Química, Universidade Federal de São Carlos, 13565-905 São Carlos - SP, Brazil
}

\begin{abstract}
Duas novas e duas conhecidas saponinas triterpênicas foram isoladas da casca do caule de Pentaclethra macroloba. As estruturas foram determinadas usando uma combinação de técnicas de RMN homo- (1D: RMN ${ }^{1} \mathrm{H}, \mathrm{RMN}^{13} \mathrm{C}-\left\{{ }^{1} \mathrm{H}\right\}, \mathrm{RMN}{ }^{13} \mathrm{C}-\mathrm{DEPT} 135 ; 2 \mathrm{D}:{ }^{1} \mathrm{H}-{ }^{1} \mathrm{H}-\mathrm{COSY},{ }^{1} \mathrm{H}-{ }^{1} \mathrm{H}-$ TOCSY, ${ }^{1} \mathrm{H}-{ }^{-1} \mathrm{H}-\mathrm{NOESY}$ ) and heteronuclear 2D (HMQC and HMBC), espectros de massas obtidos com ionização por pulverização eletrônica (ESIMS) e métodos químicos. As estruturas das duas novas saponinas triterpênicas foram estabelecidas como $3 \beta-O$ - $\{[\beta$-D-glicopiranosil-(10 3)- $\alpha$-Lramnopiranosil-(10 2)], $\beta$-D-glicopiranosil-(10 4) $\}$ - $\alpha$-L-arabinopiranosilhederagenina (3) e ácido $3 \beta$-O- $\{[\beta$-D-glicopiranosil-(10 4)- $\beta$-D-glicopiranosil-(10 3 )- $\alpha$-L-ramnopiranosil-(10 2)], $\beta$-Dglicopiranosil(10 4)\}- $\alpha$-L-arabinopiranosiloleanólico (4).
\end{abstract}

Two new and two known triterpenoid saponins were isolated from the stem bark of Pentaclethra macroloba. Their structures were determined using a combination of homo- $\left(1 \mathrm{D}{ }^{1} \mathrm{H} N M R,{ }^{13} \mathrm{C} N M R-\right.$ HBBD and ${ }^{13} \mathrm{C}$ NMR-DEPT) and heteronuclear 2D NMR techniques $\left({ }^{1} \mathrm{H}-{ }^{-} \mathrm{H}-\mathrm{COSY},{ }^{1} \mathrm{H}-{ }^{-1} \mathrm{H}-\mathrm{TOCSY}\right.$, ${ }^{1} \mathrm{H}-{ }^{-1} \mathrm{H}-\mathrm{NOESY}, \mathrm{HMQC}$ and HMBC), ESIMS and chemical methods. The structures of the two new pentacyclic triterpenoid saponins were established as $3 \beta-O-\{[\beta$-D-glucopyranosyl-(10 3)- $\alpha$-Lrhamnopyranosyl-(10 2)], $\beta$-D-glucopyranosyl-(10 4) $\}$ - $\alpha$-L-arabinopyranosylhederagenin (3) and $3 \beta-O$ - $\{[\beta$-D-glucopyranosyl-(10 4)- $\beta$-D-glucopyranosyl-(10 3 )- $\alpha$-L-rhamnopyranosyl-(10 2$)], \beta$ D-glucopyranosyl(10 4)\}- $\alpha$-L-arabinopyranosyloleanolic acid (4).

Keywords: Pentaclethra macroloba, Mimosoideae, pentacyclic triterpenoid saponins

\section{Introduction}

Pentaclethra macroloba (Willd.) Kuntze, of the family Mimosoideae, ${ }^{1,2}$ occurs in the northern region of Brazil, where it is known as "pracaxi" and is used by the local population to treat several afflictions, including snakebites. ${ }^{3}$ The first chemical and biological investigations on $P$. macroloba has shown the presence of steroids $(\beta \text {-sitosterol, stigmasterol and campesterol })^{4}$ and insecticidal properties. $^{5-7}$

In this paper we report the isolation and characterization of two known, $3 \beta-O$-[ $\beta$-D-glucopyranosyl(10 4), $\alpha$-L-rhamnopyranosyl-(10 2)]- $\alpha$-L-arabinopyranosyloleanolic acid $(\mathbf{1})^{8,9}$ and $3 \beta-O-\{[\beta-\mathrm{D}-$ glucopyranosyl-(10 3 )- $\alpha$-L-rhamnopyranosyl-(10 2$)], \beta$ -

* e-mail: braz@uenf.br
D - g lucopyranos y l-( $\left.\left.\begin{array}{lll}1 & 0 & 4\end{array}\right)\right\}-\alpha-L-a r a b i n o-$ pyranosyloleanolic acid $(2),{ }^{8}$ and two new pentacyclic triterpenoid saponins, $3 \beta-O$ - $\{[\beta$-D-glucopyranosyl-(10 3$)$ $\alpha$-L-rhamnopyranosyl-(10 2)], $\beta$-D-glucopyranosyl(10 4) $\}-\alpha$-L-arabinopyranosylhederagenin (3) and $3 \beta-O$ $\{$ [ $\beta$-D-glucopyranosyl-(10 4)- $\beta$-D-glucopyranosyl(10 3)- $\alpha$-L-rhamnopyranosyl-(10 2)], $\beta$-D-glucopyranosyl (10 4) $\}$ - $\alpha$-L-arabinopyranosyloleanolic acid (4). The two known saponins (1 and 2) are described for the first time from this species.

\section{Results and Discussion}

Two known (1 and 2) and two new triterpenoid saponins (3 and $\mathbf{4}$ ) were isolated from an ethanolic extract of the stem bark of Pentaclethra macroloba (Leguminosae- 
Mimosoideae) using a combination of silica gel, Sephadex LH-20 and reverse-phase chromatography (HPLC). The structures were established on the basis of chemical methods and spectral data. The IR spectra of the four compounds showed bands at $v_{\max } 3400$ (strong and broad, suggesting several $\mathrm{OH}$ groups) and $1700 \mathrm{~cm}^{-1}$ (carboxylic group). Additional spectral data, mainly NMR and ESMS spectra, led us to postulate the structures $\mathbf{1}-\mathbf{4}$. Oleanolic acid was identified as aglycone of saponins $\mathbf{1 , 2}$ and $\mathbf{3}$ after acid hydrolysis while hederagenin identified as aglycone of saponin $\mathbf{3}$ along with the carbohydrates arabinose, rhamnose and glucose for all compounds.
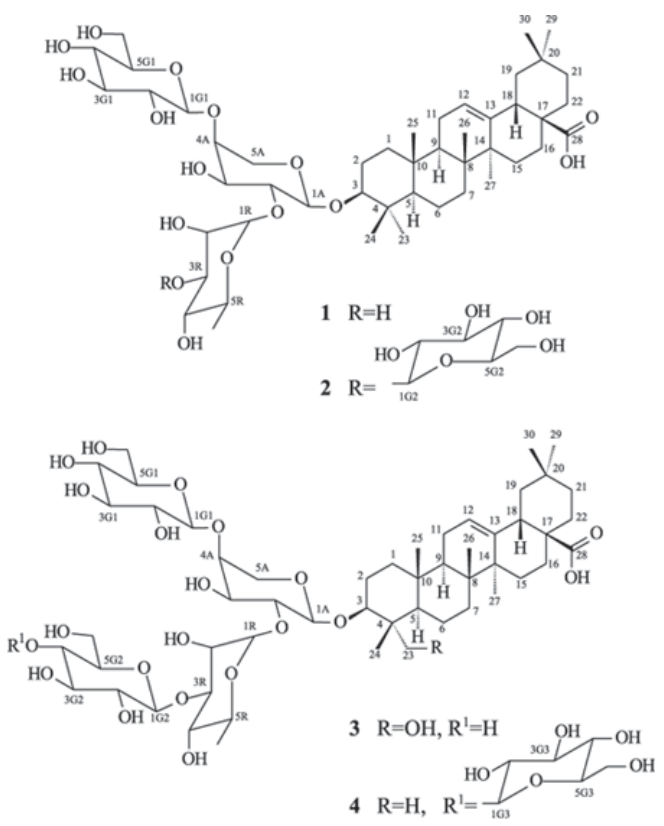

Comparative analysis of the ${ }^{13} \mathrm{C}$ NMR-HBBD and ${ }^{13} \mathrm{C}$ NMR-DEPT spectra of the four pentacyclic triterpenoid saponins was used to identify the number of signals attributed to quaternary, methine, methylene and methyl carbon atoms (Tables 1 and 2).

The known triterpene saponins $\mathbf{1}$ and $\mathbf{2}$ were identified as $3 \beta$ - $O$ - $[\beta$-D-glucopyranosyl-(10 4), $\alpha$-L-rhamnopyranosyl-(10 2)]- $\alpha$-L-arabinopyranosyloleanolic acid (1) $)^{8,9}$ and $3 \beta-O-\{[\beta-\mathrm{D}$-glucopyranosyl-(10 3$)-\alpha-\mathrm{L}-$ rhamnopyranosyl-(10 2)], $\beta$-D-glucopyranosyl-(10 4) $\}-\alpha$ L-arabinopyranosyloleanolic acid $(2)^{8}$ on the basis of spectral data, especially 1D and 2D NMR and ESIMS, and through comparison with the data available in the literature. ${ }^{8,9}$
Compound $\mathbf{3}$ was obtained as an amorphous powder. The ESIMS (negative ion mode) showed a quasimolecular ion peak at $m / z 1073\left([\mathrm{M}-\mathrm{H}]^{-}\right)$, indicating a molecular weight of $1074 \mathrm{Da}$ consistent with a molecular formula $\mathrm{C}_{53} \mathrm{H}_{86} \mathrm{O}_{22}$. Other significant negative ion peaks were observed at $m / z 911$ ([M-H-162]', 3a and 3b), 765 ([M-H162-146]', 3c), 749 ([M-H-162-162]', 3d), 603 ([M-H-162162-146] $]^{-}$and/or [M-H-162-146-162]', 3e) and 471 ([MH-162-162-162-146-132]', 3f), Scheme 1 (A). These peaks were attributed to fragments corresponding to the loss of one hexosyl $(\mathrm{m} / \mathrm{z}, 911)$, one hexosyl and one deoxyhexosyl $(\mathrm{m} / \mathrm{z}, 765)$, two hexosyl $(\mathrm{m} / \mathrm{z}, 749)$, two hexosyl and one deoxyhexosyl $(\mathrm{m} / \mathrm{z}$ 603) and two hexosyl, one deoxyhexosyl and one pentosyl $(\mathrm{m} / \mathrm{z} 471)$ radicals (Scheme 1). Based on these data we postulated the elimination of two glucopyranosyl, one rhamnopyranosyl and one arabinopyranosyl moieties to yield the aglycone ion at $\mathrm{m} / \mathrm{z} 471$ (hederagenin $-\mathrm{H}^{-}=\left[\mathrm{C}_{30} \mathrm{H}_{48} \mathrm{O}_{4}-\mathrm{H}\right]^{-}=$ $\left.\left[\mathrm{C}_{30} \mathrm{H}_{47} \mathrm{O}_{4}\right]^{-}, 3 \mathbf{f}\right)$, in accordance with the sugars arabinose, rhamnose and glucose obtained by the acid hydrolysis experiment. The peak at $\mathrm{m} / \mathrm{z}, 911$ ([M-H-glucopyranosyl] , 3a and/or 3b) suggested a terminal glucopyranosyl unit. Additional peaks at 765 ([M-H-glucopyranosylrhamnopyranosyl] $]^{-}=m / z, 911$ - rhamnopyranosyl, 3c) and 749 ([M-H-glucopyranosyl-glucopyranosyl, 3d $]^{-}=\mathrm{m} / \mathrm{z}$ 911-glucopyranosyl) revealed a branched sugar chain involving a disubstituted arabinopyranosyl moiety (Schemes 1 and 2). ${ }^{9,10}$

In fact, the hydrogen broad band decoupled (HBBD) ${ }^{13} \mathrm{C}$ NMR spectrum of $\mathbf{3}$ (Tables 1 and 2), showed 53 signals. Comparative analysis of the HBBD and DEPT ${ }^{13} \mathrm{C}$ NMR spectra allowed the identification of signals corresponding to eight quaternary $\left[(\mathrm{C})_{8:}\right.$ six $\mathrm{sp}^{3}$ and two $\mathrm{sp}^{2}$ of an olefinic double bond at $\delta_{\mathrm{C}} 144.95$ and carboxyl group at $\delta_{\mathrm{C}} 180.42$ $\left.=(\mathrm{C})_{7}(\mathrm{COOH})\right]$, twenty four methine $\left[(\mathrm{CH})_{24}\right.$ : one $\mathrm{sp}^{2}$ and twenty three $\mathrm{sp}^{3}$, including twenty oxygenated $=(\mathrm{CH})_{4}(\mathrm{O}$ $\left.\mathrm{CH})_{20}\right]$, fourteen methylene $\left[\left(\mathrm{CH}_{2}\right)_{14}:\right.$ all sp ${ }^{3}$, including four oxygenated $\left.=\left(\mathrm{CH}_{2}\right)_{10}\left(\mathrm{CH}_{2}-\mathrm{O}\right)_{4}\right]$ and seven methyl $\left[\left(\mathrm{CH}_{3}\right)_{7}\right]$ carbon atoms. Consequently, expanded formula $(\mathrm{C})_{7}(\mathrm{COOH})(\mathrm{CH})_{4}(\mathrm{O}-\mathrm{CH})_{20}\left(\mathrm{CH}_{2}\right)_{10}\left(\mathrm{CH}_{2}-\mathrm{O}\right)_{4}\left[\left(\mathrm{CH}_{3}\right)_{7}=\right.$ $\mathrm{C}_{53} \mathrm{H}_{74} \mathrm{O}_{26}$ was deduced, which after considering the presence of twelve hydroxyl groups and four ether functions was established as $\mathrm{C}_{53} \mathrm{H}_{86} \mathrm{O}_{22}$ in accordance with the ESMS. The presence of four sugar moieties was confirmed by the HMQC spectrum, which showed the anomeric ${ }^{1} \mathrm{H}$ NMR signals at $\delta_{\mathrm{H}} 4.90(\mathrm{~d}, J 7.1 \mathrm{~Hz}, \mathrm{H}-1 \mathrm{~A})$, 6.17 (br s, H-1R), 5.08 (d, J 7.9 Hz, H-1G1) and 5.46 (d, $J$ $7.8 \mathrm{~Hz}, \mathrm{H}-1 \mathrm{G} 2$ ) correlated with ${ }^{13} \mathrm{C}$ NMR signals at $\delta_{\mathrm{C}}$ 105.09, 101.67, 106.97 and 106.90, respectively. ${ }^{11}$ Complete ${ }^{1} \mathrm{H}$ and ${ }^{13} \mathrm{C}$ chemical shift assignments of each sugar unit was achieved by the ${ }^{1} \mathrm{H}-{ }^{1} \mathrm{H}-\mathrm{COSY}$, TOCSY, 
Table 1. ${ }^{1} \mathrm{H}(500 \mathrm{MHz})$ and ${ }^{13} \mathrm{C}(125 \mathrm{MHz})$ spectral data for aglycones of the compounds $\mathbf{3}$ and 4 including results obtained by heteronuclear $2 \mathrm{D}$ shift-correlated HMQC and HMBC spectra, in $\mathrm{C}_{5} \mathrm{D}_{5} \mathrm{~N}$ and TMS as internal standard. Chemical shifts $(\delta$, ppm) and coupling constants $(J$ in $\mathrm{Hz}$, in parenthesis) ${ }^{\mathrm{a}}$

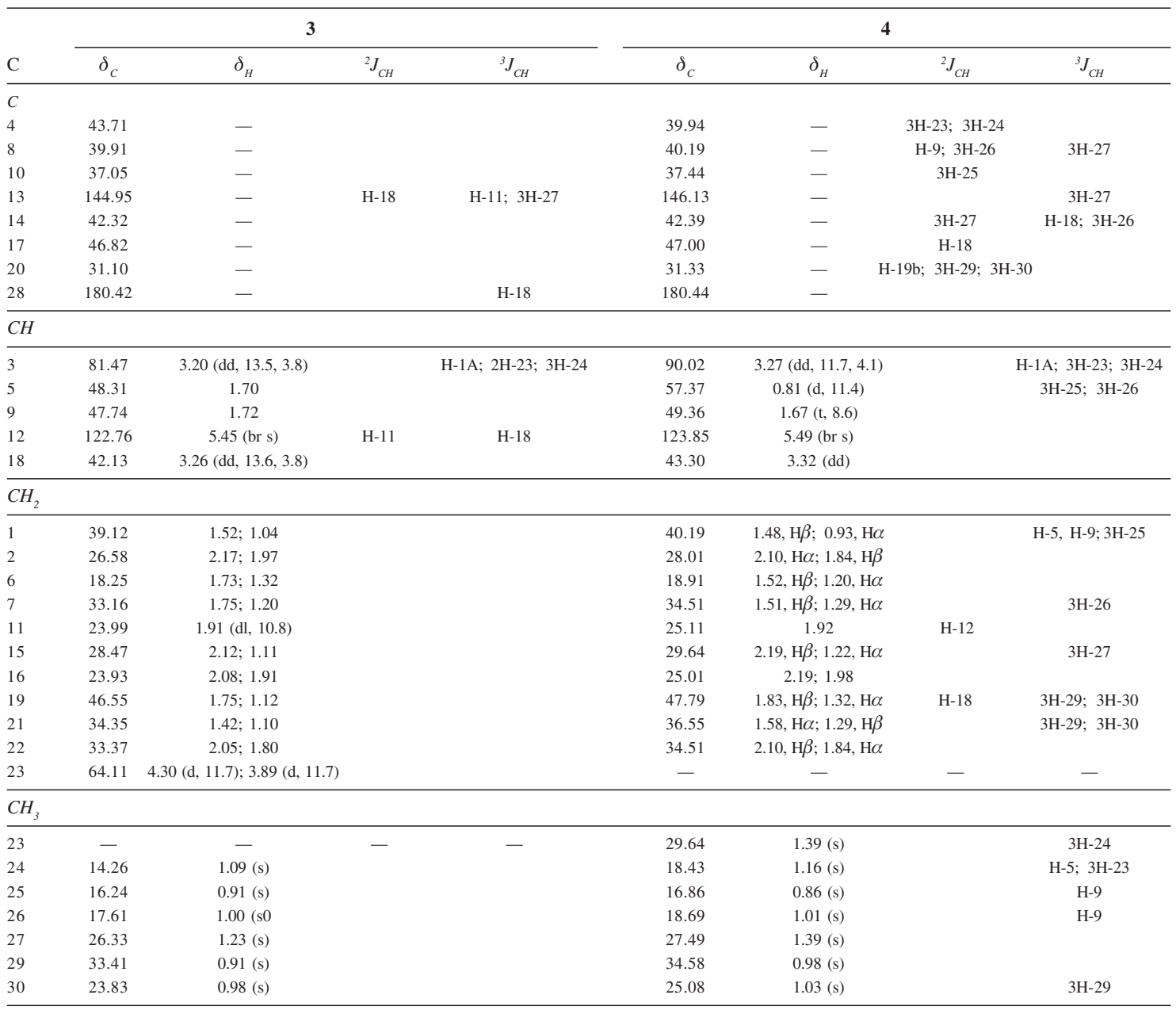

2D homonuclear ${ }^{1} \mathrm{H}-{ }^{1} \mathrm{H}-\mathrm{COSY}$ and ${ }^{1} \mathrm{H}-{ }^{1} \mathrm{H}-\mathrm{TOCSY}$ and heteronuclear HMBC (Table 2) spectra were also used for these assignments. Chemical shifts of hydrogen atoms obtained from $1 \mathrm{D}{ }^{1} \mathrm{H}$ NMR spectra. Carbon signals corresponding to $\mathrm{C}, \mathrm{CH} \mathrm{CH}_{2}$ and $\mathrm{CH}_{3}$ deduced by comparative analysis of HBBD- and DEPT- ${ }^{13} \mathrm{C}$ NMR spectra. Superimposed ${ }^{1} \mathrm{H}$ signals are described without multiplicity and chemical shifts deduced by HMQC, HMBC and ${ }^{1} \mathrm{H}-{ }^{1} \mathrm{H}-\mathrm{COSY}$.

HMQC and the HMBC spectra (Table 2). The ${ }^{1} \mathrm{H}$ NMR spectrum of $\mathbf{3}$ displayed six singlet signals of seven methyl groups at $\delta_{\mathrm{H}} 0.91,0.91,0.98,1.00,1.09$ and 1.23 , one doublet at $\delta_{\mathrm{H}} 1.56(J 6.2 \mathrm{~Hz})$, one of olefinic hydrogen in a trisubstituted double bond $\left(\delta_{\mathrm{H}} 5.45\right.$, br s) and one doubledoublet $(J 13.5,3.8 \mathrm{~Hz})$ at $\delta_{\mathrm{H}} 3.20$ attributed to the carbinolic hydrogen $\mathrm{H}-3$ located at an axial position with a coupling constant value $J=13.5 \mathrm{~Hz}$ (axial-axial interaction). These data suggested a pentacyclic triterpenoid skeleton type olean-12-ene as aglycone, ${ }^{12}$ in accordance with the signals at $\delta_{\mathrm{C}} 122.76(\mathrm{CH}-12)$ and
144.95 (C-13) observed in the ${ }^{13} \mathrm{C}$ NMR spectra (HBBD and DEPT). The ${ }^{1} \mathrm{H}$ and ${ }^{13} \mathrm{C}$ chemical shift assignments of $\mathrm{CH}-12$ and $\mathrm{CH}-3$ were unambiguously made by the cross peaks observed in the HMQC spectrum revealing correlation of the signals at $\delta_{\mathrm{H}} 5.45(\mathrm{H}-12)$ with $\delta_{\mathrm{C}} 122.76$ $(\mathrm{CH}-12)$ and $\delta_{\mathrm{H}} 3.20(\mathrm{H}-3)$ with $\delta_{\mathrm{C}} 81.47(\mathrm{CH}-3)$, which were confirmed by heteronuclear connectivity to longrange coupling revealed by $\mathrm{HMBC}$ spectrum (Table 1). The lower ${ }^{13} \mathrm{C}$ chemical shifts of the $\mathrm{CH}-3\left(\delta_{\mathrm{C}} 81.47\right), \mathrm{CH}-$ $5\left(\delta_{\mathrm{C}} 48.31\right)$ and $\mathrm{CH}_{3}-24\left(\delta_{\mathrm{C}} 14.26\right)$ when compared with those of $\mathbf{1}, 2$ and $\mathbf{4}\left[\right.$ e. g. $\delta_{\mathrm{C}} 90.02(\mathrm{CH}-3), 57.37(\mathrm{CH}-5)$ and 
Table 2. ${ }^{1} \mathrm{H}(500 \mathrm{MHz})$ and ${ }^{13} \mathrm{C}(125 \mathrm{MHz})$ for the carbohydrate moieties of the compounds 3 and 4 including results obtained by heteronuclear $2 \mathrm{D}$ shift-correlated HMQC and $\mathrm{HMBC}$ spectra, in $\mathrm{C}_{5} \mathrm{D}_{5} \mathrm{~N}$ as solvent. Chemical shifts $(\delta, \mathrm{ppm})$ and coupling constants $(J \text {, Hz, in parenthesis })^{\mathrm{a}}$

\begin{tabular}{|c|c|c|c|c|c|c|c|c|}
\hline \multirow[b]{2}{*}{$\mathrm{C}$} & \multicolumn{4}{|c|}{3} & \multicolumn{4}{|c|}{4} \\
\hline & $\delta_{C}$ & $\delta_{H}$ & ${ }^{2} J_{C H}$ & ${ }^{3} J_{C H}$ & $\delta_{C}$ & $\delta_{H}$ & ${ }^{2} J_{C H}$ & ${ }^{3} J_{C H}$ \\
\hline $1 \mathrm{~A}$ & 105.09 & $4.90(\mathrm{~d}, 7.1)$ & $\mathrm{H}-2 \mathrm{~A}$ & $\mathrm{H}-3$ & 105.60 & $4.73(\mathrm{~d}, 6.7)$ & & H-3 \\
\hline $2 \mathrm{~A}$ & 76.39 & $4.40(\mathrm{dd}, 7.1,8.2)$ & $\mathrm{H}-3 \mathrm{~A}$ & $\mathrm{H}-4 \mathrm{~A}$, & 76.39 & 4.46 & & $\mathrm{H}-1 \mathrm{R}$ \\
\hline $3 \mathrm{~A}$ & 75.16 & 3.88 & & H-5 & 74.57 & 4.18 & $\mathrm{H}-2^{\mathrm{A}}$ & $\mathrm{H}-1 \mathrm{~A}$ \\
\hline $4 \mathrm{~A}$ & 80.79 & 4.12 (br s) & $2 \mathrm{H}-5$ & H-1G1 & 80.16 & 4.28 & & $2 \mathrm{H}-5 \mathrm{~A}, \mathrm{H}-1 \mathrm{G} 1$ \\
\hline $5 \mathrm{~A}$ & 66.10 & $4.36(\mathrm{~d}, 11.7), 3.57(\mathrm{~d}, 11.7)$ & & $\mathrm{H}-1 \mathrm{~A}$ & 65.54 & $4.453 .76(\mathrm{~d}, 11.4), \mathrm{Ha}$ & & $\mathrm{H}-1 \mathrm{~A}$ \\
\hline $1 \mathrm{R}$ & 101.67 & 6.17 (br s) & & $\mathrm{H}-2 \mathrm{~A}$ & 101.92 & 6.18 (br s) & $\mathrm{H}-2 \mathrm{R}$ & $\mathrm{H}-2 \mathrm{~A}$ \\
\hline $2 \mathrm{R}$ & 71.83 & 4.96 (br s) & & & 71.81 & 4.34 (br s) & $\mathrm{H}-1 \mathrm{R}$ & \\
\hline $3 R$ & 83.00 & $4.83(\mathrm{dd}, 2.8,9.5)$ & $\mathrm{H}-2 \mathrm{R}, \mathrm{H}-4 \mathrm{R}$ & H-1R, H-1G2 & 83.44 & 4.77 (dd, 9.3, 2.6) & $\mathrm{H}-2 \mathrm{R}, \mathrm{H}-4 \mathrm{R}$ & H-1R, H-1G2 \\
\hline $4 \mathrm{R}$ & 73.05 & $4.47(\mathrm{t}, 9.5)$ & $\mathrm{H}-3 \mathrm{R}$ & $\mathrm{H}-2 \mathrm{R}, 3 \mathrm{H}-6 \mathrm{R}$ & 73.08 & 4.48 & $\mathrm{H}-3 \mathrm{R}$ & H-2R, 3H-6R \\
\hline $5 \mathrm{R}$ & 70.02 & $4.69(\mathrm{dq}, 9.5,6.2)$ & & $\mathrm{H}-1 \mathrm{R}$ & 70.02 & $4.65(\mathrm{~m})$ & $3 \mathrm{H}-6 \mathrm{R}$ & \\
\hline $6 \mathrm{R}$ & 18.74 & $1.56(\mathrm{~d}, 6.2)$ & $\mathrm{H}-5 \mathrm{R}$ & $\mathrm{H}-4 \mathrm{R}$ & 18.75 & $1.59(\mathrm{~d}, 6.2)$ & & $\mathrm{H}-4 \mathrm{R}$ \\
\hline $1 \mathrm{G} 1$ & 106.97 & $5.08(\mathrm{~d}, 7.9)$ & $\mathrm{H}-2 \mathrm{G} 1$ & & 106.79 & $5.14(\mathrm{~d}, 7.9)$ & $\mathrm{H}-2 \mathrm{G} 1$ & \\
\hline $2 \mathrm{G} 1$ & 76.00 & $4.01(\mathrm{dd}, 7.9,9.1)$ & H-3G1 & & 75.67 & $4.04(\mathrm{dd}, 7.9,8.2)$ & & \\
\hline $3 \mathrm{G} 1$ & 78.62 & $4.19(\mathrm{t}, 9.1)$ & H-2G1, H-4G1 & & 78.67 & 4.22 & $\mathrm{H}-2 \mathrm{G} 1$ & \\
\hline $4 \mathrm{G} 1$ & 71.41 & $4.17(\mathrm{t}, 9.1)$ & & & 71.53 & 4.26 & & \\
\hline $5 \mathrm{G} 1$ & 78.93 & 3.88 & & & 78.91 & $3.92(\mathrm{~m})$ & $\mathrm{H}-3 \mathrm{G} 3$ & \\
\hline $6 \mathrm{G} 1$ & 62.72 & $4.47,4.34(\mathrm{dd}, 11.9,4.9)$ & & $\mathrm{H}-4 \mathrm{G} 1$ & 62.77 & $4.52,4.39$ & & \\
\hline $1 \mathrm{G} 2$ & 106.90 & $5.46(\mathrm{~d}, 7.8)$ & $\mathrm{H}-2 \mathrm{G} 2$ & $\mathrm{H}-3 \mathrm{R}$ & 107.01 & $5.45(\mathrm{~d}, 7.9)$ & $\mathrm{H}-2 \mathrm{G} 2$ & $\mathrm{H}-3 \mathrm{R}$ \\
\hline $2 \mathrm{G} 2$ & 75.63 & $4.09(\mathrm{dd}, 7.8,9.1)$ & $\mathrm{H}-3 \mathrm{G} 2$ & & 76.07 & $4.11(\mathrm{dd}, 7.9,8.4)$ & $\mathrm{H}-3 \mathrm{G} 2$ & \\
\hline $3 \mathrm{G} 2$ & 78.62 & $4.21(\mathrm{t}, 9.1)$ & $\mathrm{H}-2 \mathrm{G} 2$ & $\mathrm{H}-1 \mathrm{G} 2$ & 78.67 & 4.38 & $\mathrm{H}-2 \mathrm{G} 2, \mathrm{H}-4 \mathrm{G} 2$ & \\
\hline $4 \mathrm{G} 2$ & 71.67 & $4.19(\mathrm{t}, 9.1)$ & & & 71.67 & 4.35 & $\mathrm{H}-3 \mathrm{G} 2$ & $\mathrm{H}-1 \mathrm{G} 3$ \\
\hline $5 \mathrm{G} 2$ & 78.69 & 3.95 & & & 78.64 & $3.95(\mathrm{~m})$ & $\mathrm{H}-4 \mathrm{G} 2$ & \\
\hline $6 \mathrm{G} 2$ & 62.72 & $4.49,4.27(\mathrm{dd}, 11.6,5.2)$ & & & 63.29 & $4.56(\mathrm{dd}, 12.0,3.5), 4.46$ & & \\
\hline $1 \mathrm{G} 3$ & - & - & - & - & 106.27 & $5.19(\mathrm{~d}, 7.8)$ & $\mathrm{H}-2 \mathrm{G} 3$ & $\mathrm{H}-4 \mathrm{G} 2$ \\
\hline $2 \mathrm{G} 3$ & - & - & - & - & 76.05 & $4.08(\mathrm{dd}, 7.8,8.40$ & & \\
\hline $3 \mathrm{G} 3$ & - & - & - & - & 79.55 & 4.20 & $\mathrm{H}-4 \mathrm{G} 3$ & \\
\hline $4 \mathrm{G} 3$ & - & - & - & - & 72.88 & 4.19 & $\mathrm{H}-3 \mathrm{G} 3$ & H-1G3 \\
\hline $5 \mathrm{G} 3$ & - & - & - & - & 79.71 & $4.00(\mathrm{~m})$ & & \\
\hline $6 \mathrm{G} 3$ & - & - & - & - & 63.29 & 4.284 .52 & & \\
\hline
\end{tabular}

${ }^{\text {a Homonuclear }}{ }^{1} \mathrm{H}-{ }^{1} \mathrm{H}-\mathrm{COSY},{ }^{1} \mathrm{H}-{ }^{1} \mathrm{H}$-TOCSY and ${ }^{1} \mathrm{H}-{ }^{13} \mathrm{C}-\mathrm{COSY}-{ }^{1} J_{\mathrm{CH}}$ (Table 1 ) spectra were also used for these assignments. Chemical shifts of hydrogen atoms obtained from $1 \mathrm{D}{ }^{1} \mathrm{H}$ NMR spectra. Carbon signals corresponding to $\mathrm{C}, \mathrm{CH}, \mathrm{CH}_{2}$ and $\mathrm{CH}_{3}$ deduced by comparative analysis of HBBD- and DEPT- ${ }^{13} \mathrm{C}$ NMR spectra. Superimposed ${ }^{1} \mathrm{H}$ signals are described without multiplicity and chemical shifts deduced by HMQC, HMBC, ${ }^{1} \mathrm{H}-{ }^{1} \mathrm{H}-\mathrm{COSY}$ and ${ }^{1} \mathrm{H}-{ }^{1} \mathrm{H}-\mathrm{TOCSY}$.

$18.43\left(\mathrm{CH}_{3}-24\right.$, Table 1] revealed the $\gamma$-effects, ${ }^{13,14}$ of the hydroxy function presence in the hydroxymethylene group $\mathrm{HOCH}_{2}-23\left[\delta_{\mathrm{C}} 64.11, \delta_{\mathrm{H}} 4.30(\mathrm{~d}, J 11.7 \mathrm{~Hz})\right.$ and 3.89 $(\mathrm{d}, J 11.7 \mathrm{~Hz})]$. This result was confirmed by the HMQC and HMBC spectra (Table 2). The characterization of the [ $\beta$-D-glucopyranosyl-(10 3)- $\alpha$-L-rhamnopyranosyl(10 2)], $\beta$-D-glucopyranosyl-(10 4) $\}$ - $\alpha$-L-arabinopyranosyl moiety and its placement at $\mathrm{CH}-3$ were mostly based on the HMBC spectrum, which revealed cross peaks corresponding to heteronuclear spin-spin interaction between (Table 2): a) CH-3 $\left(\delta_{\mathrm{C}} 81.47\right)$ and H-1A (4.90) and $\mathrm{CH}-1 \mathrm{~A}\left(\delta_{\mathrm{C}} 105.09\right)$ and $\mathrm{H}-3\left(\delta_{\mathrm{H}} 3.20\right)$; b $) \mathrm{CH}-1 \mathrm{R}\left(\delta_{\mathrm{C}} 101.67\right)$ and $\mathrm{H}-2 \mathrm{~A}\left(\delta_{\mathrm{H}} 4.40\right)$; c) $\mathrm{CH}-4 \mathrm{~A}\left(\delta_{\mathrm{C}} 80.79\right)$ and $\mathrm{H}-1 \mathrm{G} 1\left(\delta_{\mathrm{H}}\right.$ $5.08)$; d) $\mathrm{CH}-3 \mathrm{R}\left(\delta_{\mathrm{C}} 83.00\right)$ and both $\mathrm{H}-1 \mathrm{R}\left(\mathrm{d}_{\mathrm{H}} 6.17\right)$ and $\mathrm{H}-$ $1 \mathrm{G} 2\left(\delta_{\mathrm{H}} 5.46\right)$; e) $\mathrm{CH}-1 \mathrm{G} 2\left(\delta_{\mathrm{C}} 106.90\right)$ and $\mathrm{H}-3 \mathrm{R}\left(\delta_{\mathrm{H}} 4.83\right)$. In addition, we observed heteronuclear correlation of methyl signal at $\delta_{\mathrm{H}} 1.57(\mathrm{~d}, J 6.2 \mathrm{~Hz})$ with $\mathrm{d}_{\mathrm{C}} 18.74$ in the HMQC and both CH-4R $\left(\delta_{\mathrm{C}} 73.05,{ }^{3} J_{\mathrm{CH}}\right)$ and $\mathrm{CH}-5 \mathrm{R}\left(\delta_{\mathrm{C}}\right.$ $\left.70.02,{ }^{2} J_{\mathrm{CH}}\right)$ in the $\mathrm{HMBC}$, in accordance with the presence of the rhamnose. Other heteronuclear long-range couplings observed in the HMBC spectrum of $\mathbf{3}$ are summarized in Table 2.

Therefore, the structure of the new pentacyclic triterpenoid glycoside was characterized as $3 \beta-O-\{[\beta-\mathrm{D}$ glucopyranosyl-(10 3)- $\alpha$-L-rhamnopyranosyl-(10 2)], $\beta$ D-glucopyranosyl-(10 4) $\}$ - $\alpha$-L-arabinopyranosylhederagenin (3) on the basis of spectral data (including evaluation of spin-spin coupling deduced by $1 \mathrm{D}{ }^{1} \mathrm{H}$ NMR analysis involving confirmation by ${ }^{1} \mathrm{H}-{ }^{1} \mathrm{H}-\mathrm{COSY}$, TOCSY and ${ }^{1} \mathrm{H}-{ }^{1} \mathrm{H}$-NOESY) together with the identification of the aglycone hederagenin and sugars obtained (arabinose, rhamnose and glucose) from saponin hydrolysates.

Comparison of the ${ }^{1} \mathrm{H}$ and ${ }^{13} \mathrm{C}$ spectral data of the saponin 4 (amorphous colorless solid) with those of $\mathbf{3}$ (Tables 1 and 2) indicated that the $\mathrm{CH}_{2} \mathrm{OH}$ group $\left[\delta_{\mathrm{C}} 64.11\right.$; $\delta_{\mathrm{H}} 4.30(\mathrm{~d}, J 11.7 \mathrm{~Hz})$ and $\left.3.89(\mathrm{~d}, J 11.7 \mathrm{~Hz})\right]$ in 3 was replaced by a methyl group $\left(\delta_{\mathrm{H}} 1.39\right.$ and $\left.\mathrm{d}_{\mathrm{C}} 29.64\right)$ in 4 . This hypothesis was confirmed by the ${ }^{13} \mathrm{C}$ chemical shifts 


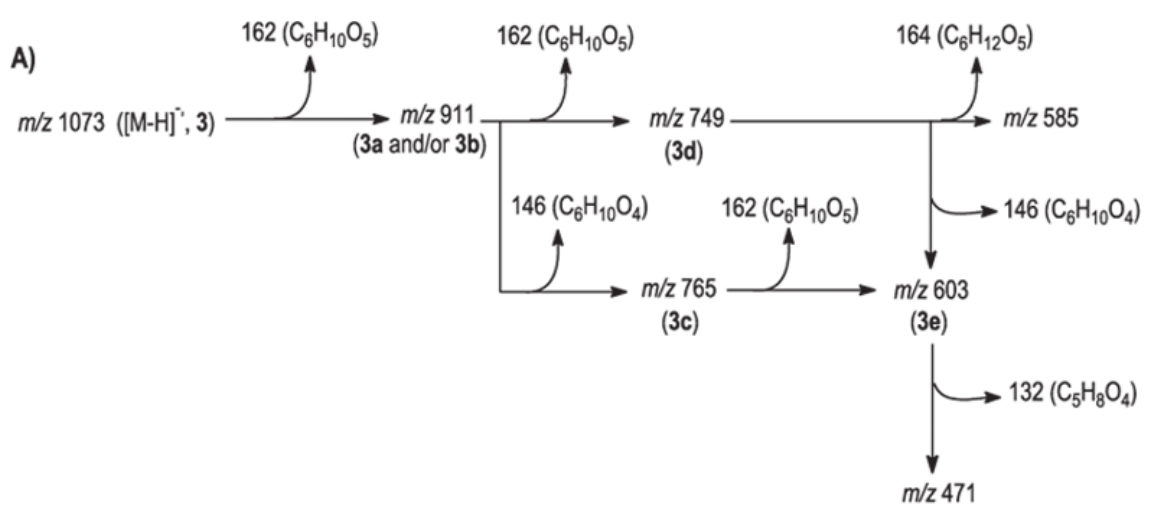

(3f)

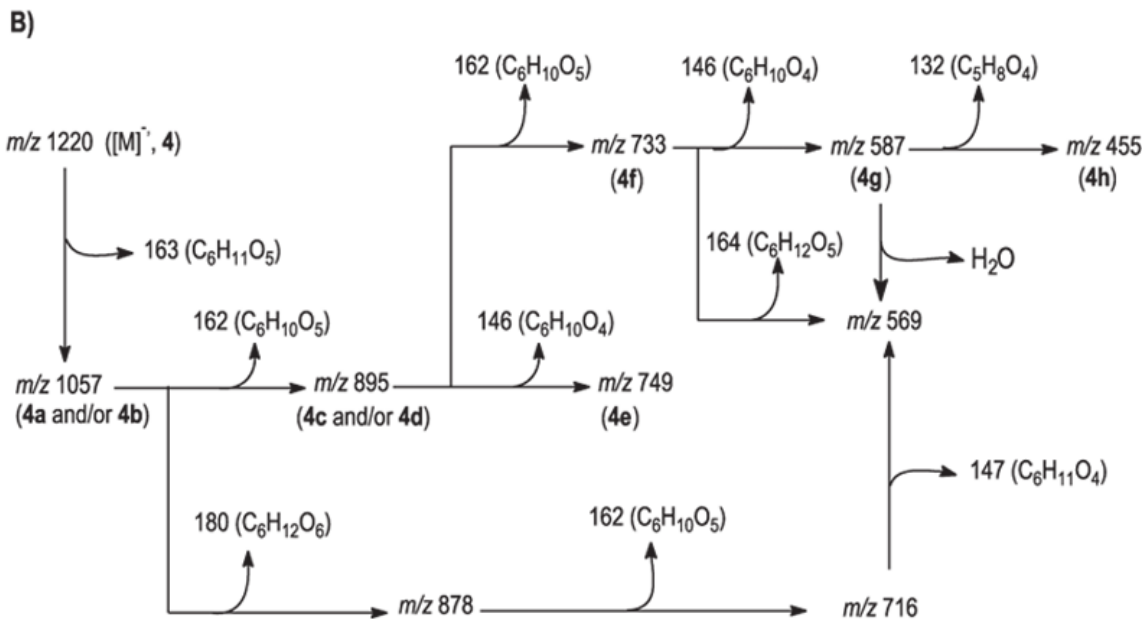

Scheme 1. Arithmetical analysis of ESMS of 3 (A) and 4 (B).

of the CH-3 at $\delta_{\mathrm{C}} 90.02\left(\delta_{\mathrm{C}} 81.47\right.$ in 3), CH-5 at $\delta_{\mathrm{C}} 57.37$ $\left(\delta_{\mathrm{C}} 48.31\right.$ in 3) and $\mathrm{CH}_{3}-24$ at $\delta_{\mathrm{C}} 18.43\left(\delta_{\mathrm{C}} 14.26\right.$ in 3), which indicated absence of the $\gamma$-effects of a hydroxy function of hydroxymethylene group $\mathrm{HOCH}_{2}-23$ in a $3 \beta$ $O$-glycosylated aglycone. ${ }^{13,14}$ Significant additional differences observed in the comparative analysis of the NMR spectra of $\mathbf{3}$ and $\mathbf{4}$ were justified by oligosaccharide moiety, containing the triterpenoid $\mathbf{4}$ the same type and sequence the sugars chain as saponin $\mathbf{3}$ and one additional glucopyranosyl group (Table 2). These deductions were confirmed by ESIMS (negative ion mode) of $\mathbf{4}$, which showed a molecular ion peak at $m / z, 1220$ ([M]') compatible with a molecular formula $\mathrm{C}_{59} \mathrm{H}_{96} \mathrm{O}_{26}$ (molecular weight $1220 \mathrm{Da})$. Other significant negative ion peaks were observed at $\mathrm{m} / \mathrm{z} 1057$ ([M-163]', 4a and/or 4b), 895 ([M163-162]', 4c and/or 4d), 749 ([M-163-162-146]', 4e), 733
([M-163-162-162]', 4f), 587 ([M-163-162-162-146]', 4g) and 455 ([M-163-162-162-146-132]', 4h), corresponding to the loss of one hexosyl, two hexosyl, three hexosyl, three hexosyl and one deoxyhexosyl and three hexosyl, one deoxyhexosyl and one pentosyl moieties, respectively, as revealed by the arithmetical analysis summarized in Scheme 1(B).

The hydrogen broad band decoupled HBBD- ${ }^{13} \mathrm{C}$ NMR spectrum of 4 (Tables 1 and 2) showed 59 signals, which were identified as corresponding to quaternary, methine, methylene and methyl carbon atoms by comparative analysis involving the DEPT- ${ }^{13} \mathrm{C}$ NMR spectrum (Tables 1 and 2). The presence of the additional sugar moiety bonded to carbon $\mathrm{CH}-4$ of the glucopyranosyl G2 was deduced from the 2D NMR experiments [heteronuclear HMQC and HMBC (Table 2) and homonuclear ${ }^{1} \mathrm{H}-{ }^{1} \mathrm{H}-\mathrm{COSY}$, TOCSY 

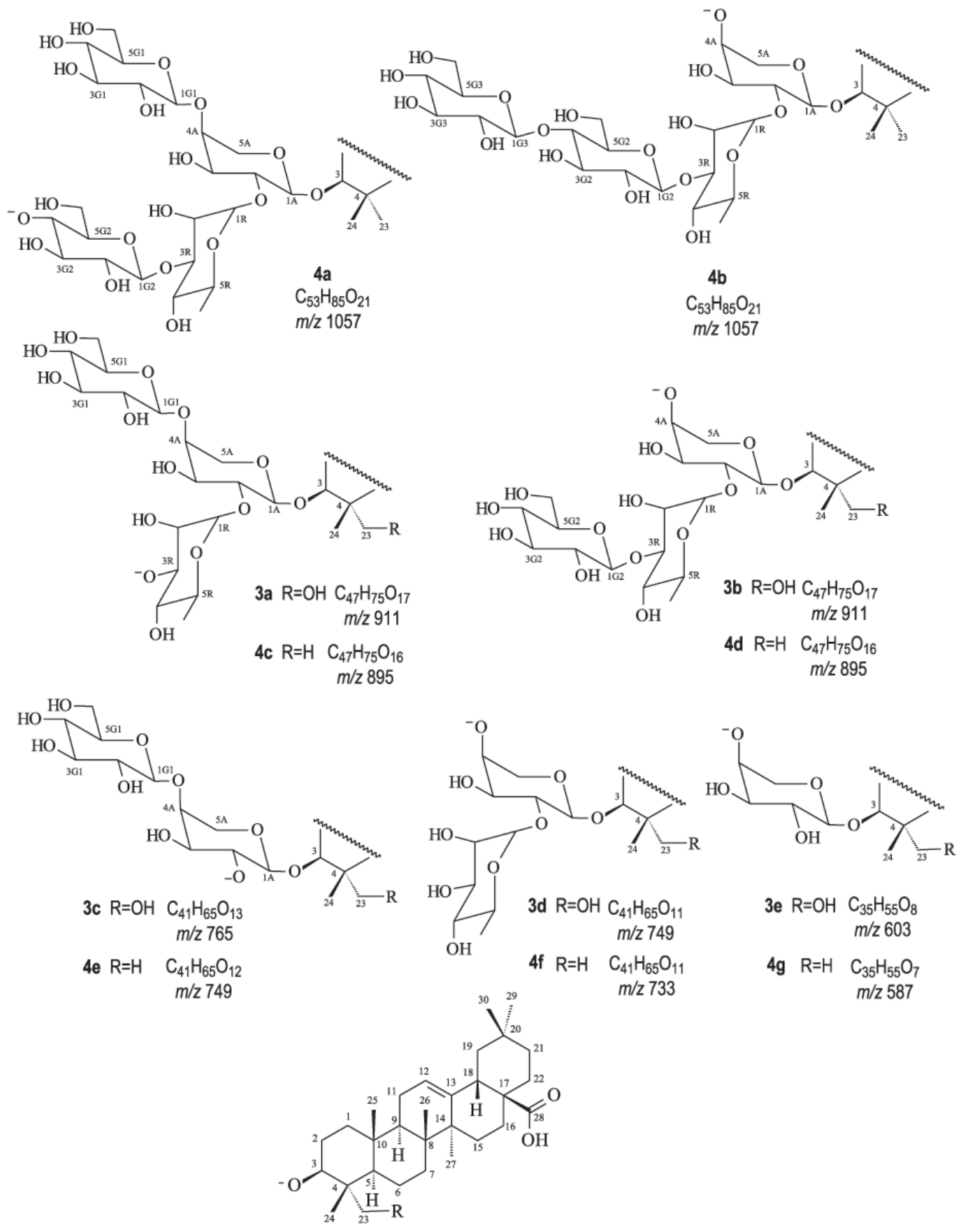

3f $\mathrm{R}=\mathrm{OH} \quad \begin{array}{r}\mathrm{C}_{30} \mathrm{H}_{47} \mathrm{O}_{4} \\ \mathrm{~m} / \mathrm{z} 471\end{array}$

4h $\mathrm{R}=\mathrm{H} \quad \mathrm{C}_{30} \mathrm{H}_{47} \mathrm{O}_{3}$ $\mathrm{m} / \mathrm{z} 455$

Scheme 2. Anion fragments proposed to justify the main peaks observed in the ESMS of $\mathbf{3}$ and $\mathbf{4}$. 
and NOESY). The single hydrogen spin systems for each sugar residue were delineated by ${ }^{1} \mathrm{H}-{ }^{1} \mathrm{H}-\mathrm{COSY}$, TOCSY and HMQC experiments and comparison with those of the depicted methyl pyranosides, ${ }^{15}$ taking into account the known effects of glycosidation (Table 2).

The values corresponding to vicinal spin-spin interaction $\left({ }^{3} J_{\mathrm{H}, \mathrm{H}}\right)$ between the anomeric hydrogens of arabinopyranosyl [J $7.1(3)$ and $6.7 \mathrm{~Hz}(4)]$ and glucopyranosyl $(J 7.8$ to $7.9 \mathrm{~Hz})$ moieties are consistent with axial-axial couplings and, consequently, the configuration of the anomeric carbons was defined as $\beta$ for glucose and $\alpha$ for arabinose.

Thus, the structure 3-O-\{ $\beta$-D-glucopyranosyl-(10 4)$\beta$-D-glucopyranosyl-(10 3)- $\alpha$-L-rhamnopyranosyl(10 2)]-[ $\beta$-D-glucopyranosyl-(10 4) $\}$ - $\alpha$-L-arabinopyranosyloleanolic acid (4) was established.

\section{Experimental}

\section{General experimental procedures}

NMR spectra were run on a Bruker Advance 500 (500 $\mathrm{MHz}$ for ${ }^{1} \mathrm{H}$ and $125 \mathrm{MHz}$ for $\left.{ }^{13} \mathrm{C}\right)$ in pyridine- $d_{5}\left(\mathrm{C}_{5} \mathrm{D}_{5} \mathrm{~N}\right)$ and residual $\mathrm{C}_{5} \mathrm{D}_{5} \mathrm{~N}$ used as internal references $(\mathrm{CH}-2 / \mathrm{CH}-$ 6: $\delta_{\mathrm{H}} 8.64$ and $\delta_{\mathrm{C}}$ 149.80). ESI-MSMS data were collected in a triple quadrupole Micromass QuattroLC instrument equipped with a "Z-spray" ion source (Micromass, Wythenshawe, Manchester, UK). A Shimadzu LC10AD HPLC pump was used to deliver methanol-water [7:3] solutions at $70 \mu \mathrm{L} / \mathrm{min}$ to the mass spectrometer. The desolvation and ion source block temperatures were set, respectively, at 350 and $140{ }^{\circ} \mathrm{C}$. Gaseous $\mathrm{N}_{2}$ was used as nebulizer $(80 \mathrm{~L} / \mathrm{h})$ and desolvation $(450 \mathrm{~L} / \mathrm{h})$. The optimal voltages found for the probe and ion source components to produce maximum intensity of the ions $[\mathrm{M}-\mathrm{H}]-$ were $3.2 \mathrm{kV}$ for the stainless steel capillary, $39 \mathrm{~V}$ for the sample cone, and $9 \mathrm{~V}$ for the extractor cone. The tandem mass spectrometry experiments were performed by adding Ar in the collision cell to produce a pressure of $2 \times 10^{-3} \mathrm{mBarr}$ for $\mathrm{CAD}$. The optimal collisional energies (CE) used for decomposition of the ions [M-H] $]^{-}$generated from saponins 1-4 were $35 \mathrm{eV}$.

\section{Plant material}

The stem bark of Pentaclethra macroloba was collected in September 1997 in Macapá, Amapá, Brazil. The plant was identified by Dr. Afrânio G. Fernandes and a voucher specimen (no. EAC-25947) is deposited in the Herbarium Prisco Bezerra of the Departamento de Biologia, Universidade Federal do Ceará, Brazil.

\section{Extraction and isolation of constituents}

The dried and powdered stem bark of Pentaclethra macroloba $(800 \mathrm{~g})$ was defatted with $n$-hexane and extracted with ethanol at room temperature. After removal of the solvent by evaporation under reduced pressure, the EtOH extract (26 g) was obtained. This extract was submitted to column chromatography on silica gel eluted with mixtures of $\mathrm{CHCl}_{3}-\mathrm{CH}_{3} \mathrm{OH}-\mathrm{H}_{2} \mathrm{O}$ (9:1:0.1) increasing the quantity of $\mathrm{MeOH}$, yielding 126 fractions. Fraction 28/36 (2.4 g) was rechromatographed on silica gel column cromatography eluted with $\mathrm{CHCl}_{3}-\mathrm{CH}_{3} \mathrm{OH}$ (8:2), yielding saponin 1 (55 mg); fraction 41/52 (430 mg) was solubilized in $\mathrm{MeOH}(1.5 \mathrm{~mL})$ and precipitated in $\mathrm{Me}_{2} \mathrm{CO}(3 \times 30 \mathrm{~mL})$, yielding $295 \mathrm{mg}$ of a crude saponin mixture, which was chromatographed on a Sephadex LH-20 column eluting by $\mathrm{MeOH}$ to yield a white power $(160 \mathrm{mg}$ ); further separation of this fraction $(150 \mathrm{mg}$ ) was performed by successive HPLC on a WATERS RP-8 semipreparative ( $7 \mu \mathrm{m}, 7.8 \times 150 \mathrm{~mm}$ ) eluted with $\mathrm{CH}_{3} \mathrm{CN}-\mathrm{H}_{2} \mathrm{O}$ [linear gradient 35:65 (v/v) to $65: 35(\mathrm{v} / \mathrm{v})$ for time $25 \mathrm{~min}$ ] to furnish compounds 2 (47.5mg), 3 (17.5 mg) and $\mathbf{4}(15.1 \mathrm{mg})$.

$3 \beta$-O-[ $\beta$-D-glucopyranosyl-(10 4)- $\alpha$-L-rhamnopyranosyl-(10 2)]- $\alpha$-L-arabinopyranosyloleanolic acid (1). Spectral data in agreement with literature values. ${ }^{8,9}$

$3 \beta$-O- $\{[\beta-D$-glucopyranosyl-(10 3)- $\alpha$-L-rhamnopyranosyl-(10 2)]- $\beta$-D-glucopyranosyl-( 104$)\}-\alpha-L$ arabinopyranosyloleanolic acid (2). Spectral data in agreement with literature values. ${ }^{8}$

$3 \beta$-O- $\{[\beta$-D-glucopyranosyl-(10 3)- $\alpha$-L-rhamnopyranosyl-(102)], $\beta$-D-glucopyranosyl-(104)\}- $\alpha-L$ arabinopyranosylhederagenin (3). Amorphous colorless solid, mp 261-268 ${ }^{\circ} \mathrm{C} ;[\alpha]_{\mathrm{D}}-3.0^{\circ}(c 0.5, \mathrm{MeOH})$; ESIMS: Schemes 1 and $2 ;{ }^{1} \mathrm{H}$ and ${ }^{13} \mathrm{C}$ NMR spectral data: Tables 1 and 2 .

$3 \beta-\mathrm{O}-\{[\beta-D$-glucopyranosyl-(10 4)- $\beta$-D-glucopyranosyl-(10 3)- $\alpha$-L-rhamnopyranosyl-(10 2)], $\beta$ - $D$ glucopyranosyl (10 4)\}- $\alpha$-L-arabinopyranosyloleanolic acid (4). Amorphous colorless solid, mp 245-247 ${ }^{\circ} \mathrm{C} ;[\alpha]_{\mathrm{D}}$ $-0.004^{\circ}(\mathrm{MeOH})$; ESIMS: Schemes 1 and $2 ;{ }^{1} \mathrm{H}$ and ${ }^{13} \mathrm{C}$ NMR spectral data: Tables 1 and 2.

\section{Acid hydrolysis}

A solution of the isolated saponin $(5 \mathrm{mg})$ in $2 \mathrm{~N} \mathrm{HCl}-$ $\mathrm{MeOH}(8 \mathrm{~mL})$ was refluxed for $3 \mathrm{~h}$, the reaction mixture was cooled to room temperature, diluted with $\mathrm{H}_{2} \mathrm{O}(20 \mathrm{~mL})$ and extracted with EtOAc. The combined EtOAc extracts were washed with $\mathrm{H}_{2} \mathrm{O}$, dried over anhydrous $\mathrm{Na}_{2} \mathrm{SO}_{4}$ and then evaporated to dryness in vacuo. The aqueous layer was neutralized with aqueous $\mathrm{NaOH} 2 \%$ and concentrated under 
reduced pressure; the residue was compared with a standard mixture of the sugars arabinose, glucose and rhamnose using silica gel TLC and $\mathrm{CH}_{2} \mathrm{Cl}_{2}-\mathrm{MeOH}-\mathrm{H}_{2} \mathrm{O}(6: 4: 0.5)$ as solvent. Furthermore, the mole ratio of each sugar was determined using RI detection in HPLC (Shodex RS pak DC-613, 75\% $\mathrm{CH}_{3} \mathrm{CN}, 1 \mathrm{~mL} \mathrm{~min}^{-1}, 50{ }^{\circ} \mathrm{C}$ ) by comparison with authentic samples of the sugars $\left(10 \mathrm{mmol} \mathrm{L}^{-1}\right.$ each of Ara, Glc and Rha). The retention time of each sugar was as follows: Ara $6.0 \mathrm{~min}$; Glc $7.4 \mathrm{~min}$ and Rha $4.8 \mathrm{~min}$.

\section{Acknowledgements}

The authors are grateful to CAPES, BNB (Banco do Nordeste do Brasil), CNPq and FAPERJ for grants, to CNPq for fellowship research, Prof. Afrânio Gomes Fernandes for botanical identification of the plant and to the Instituto de Pesquisa do Estado do Amapá-AP (Brazil).

\section{References}

1. Allen, O. N.; Allen, E. K.; The Leguminosae: A Source Book of Characteristics, Uses, and Nodulation, University of Wisconsin Press: Madison, Wisconsin, 1981.

2. Harborne, J. B.; Buckinghan, J.; Bisby, F. A.; Phytochemical Dictionary of the Leguminosae, Chapman \& Hall: London, 1994.

3. Correia, M. P.; Dicionário das Plantas Úteis do Brasil e das Exóticas Cultivadas, Ministério da Agricultura: Rio de Janeiro, 1980.
4. Lago, R. C. A.; Bol. Tec. Cent. Tecnol. Agric. Aliment. 1980, 14,1 .

5. Chun, J.; Goodman, C. L.; Rice, W. C.; McIntoshi, A. H.; Chippendale, G. M.; Schubert, K. R.; J. Econ. Entomol. 1994, 87, 1754.

6. Rathburn, H. B.; Czapla, T. H.; Schubert, K. R.; PCT Int. Appl. WO 97 19109, 1997.

7. Schubert, K. R.; Chen, R.; Czapla, T. H.; PCT Int. Appl. WO 99 15009, 1999.

8. Schenkel, E. P.; Werner, W.; Schulte, K. E.; Planta Med. 1991, $57,463$.

9. Ekabo, O. A.; Farnsworth, N. R.; Mao, G.; Mukherjee, R.; J. Nat. Prod. 1996, 59, 431.

10. Hostettmann, K.; Wolfender, J. L.; Pestic. Sci. 1997, 51, 471.

11. Agrawal, P.K.; Phytochemistry 1992, 31, 3307.

12. Maratto, S. B.; Kundu, A. P.; Phytochemistry 1994, 37, 1517.

13. Kizu, H.; Kitayama, S.; Nakatani, F.; Tamimori, T.; Namba, T.; Chem. Pharm. Bull. 1985, 33, 3324.

14. Srivastava, S. K.; Jain, D. C.; Phytochemistry 1989, $28,644$.

15. Seo, S.; Tomita, Y.; Tori, K.; Yoshimura, Y.; J. Am. Chem. Soc. 1978, 100, 3331 .

Received: November 3, 2003 Published on the web: May 28, 2004

FAPESP helped in meeting the publication costs of this article. 